(c) 2017 Universidad Nacional Autónoma de México, Facultad de Estudios Superiores Zaragoza.

Este es un artículo Open Access bajo la licencia CC BY-NC-ND (http://creativecommons.org/licenses/by-nc-nd/4.0/).

TIP Revista Especializada en Ciencias Químico-Biológicas, 20(1): 27-39, 2017.

DOI: 10.1016/j.recqb.2016.11.003

\title{
Consideraciones Generales en el ESTABLECIMIENTO DEL SEXO EN MAMÍFEROS
}

\author{
Verónica Díaz-Hernández ${ }^{1 *}$ y Horacio Merchant-Larios ${ }^{2}$ \\ 1'Depto. de Embriología, Facultad de Medicina, Universidad Nacional Autónoma de México, \\ Ciudad Universitaria, Deleg. Coyoacán, C.P. 04510, Ciudad de México, México. ${ }^{2}$ Depto. de \\ Biología Celular y Fisiología, Instituto de Investigaciones Biomédicas, Ciudad Universitaria, \\ Deleg. Coyoacán, C.P. 04510, Ciudad de México, México. E-mail: *roveazdih@yahoo.com.mx
}

\begin{abstract}
Resumen
El establecimiento del sexo en mamíferos ocurre al momento de la fertilización, sin embargo, se requiere de la determinación y diferenciación sexual de la gónada para que se establezca el fenotipo sexual del individuo. A partir del descubrimiento del gen Sry como el factor determinante del testículo se ha avanzado en conocer los mecanismos que conducen al desarrollo testicular y al establecimiento del fenotipo masculino. Y aunque el fenotipo femenino se adquiere aun en ausencia de la gónada, se requiere de la diferenciación y maduración ovárica para la adquisición de los caracteres sexuales secundarios. Este trabajo tiene como objetivo describir los mecanismos involucrados en la determinación sexual de la gónada e integrarlos con los aspectos histológicos que contribuyen con la diferenciación sexual gonadal. Una vez establecido el sexo gonadal se abordan aspectos moleculares involucrados en la masculinización del individuo. Finalmente se hace una breve revisión sobre los procesos patológicos resultantes de la alteración del establecimiento del sexo en humanos.
\end{abstract}

Palabras Clave: determinación sexual, diferenciación sexual, gónada, ovario, testículo.

\section{A consideration of the establishment of sex in mammals}

\begin{abstract}
Establishment of sex in mammals occurs at the moment of fertilization, however, the determination and sexual differentiation of the gonad is required in order to establish the sexual phenotype of the individual. Since the discovery of the Sry gene as the testis-determining factor, progress has been made in understanding the mechanisms that lead to testicular development and establishment of the male phenotype. Although the female phenotype is acquired even in the absence of the gonad, differentiation and ovarian maturation are required for the establishment of secondary sexual characteristics. This work aims to describe the mechanisms involved in sexual determination of the gonad and integrate them with the histological aspects that contribute to gonadal sex differentiation. Once the gonadal sex is established, molecular aspects involved in the masculinization of the individual are addressed. Finally, a brief review of the pathological processes resulting from the alteration of the establishment of sex in humans is undertaken.
\end{abstract}

Key Words: sex determination, sex differentiation, gonad, ovary, testicle.

Nota: Artículo recibido el 29 de marzo de 2016 y aceptado el 04 de octubre de 2016. 


\section{INTRODUCCIÓN}

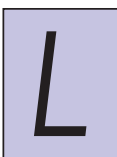

AS TRES ETAPAS DEL ESTABLECIMIENTO DEL SEXO EN MAMÍFEROS

El establecimiento del sexo durante el desarrollo de los mamíferos consiste de tres etapas secuenciales. La primera es el sexo genético o cromosómico que ocurre como consecuencia de la fertilización, el ovocito contribuye con un cromosoma sexual $\mathrm{X}$, mientras que el espermatozoide aporta alguno de los dos cromosomas sexuales, X o Y. Así los embriones pueden ser XX o XY y desarrollarán un fenotipo femenino o masculino, respectivamente.

La segunda etapa corresponde a la determinación sexual gonadal en la cual ocurren procesos moleculares que encaminan a la diferenciación de un ovario o un testículo. La presencia del gen Sry en el cromosoma sexual Y induce el aumento de expresión del gen $\operatorname{Sox} 9$ encargado de iniciar una cascada de expresión génica, que dirige a la diferenciación testicular. La ausencia del gen Sry en las mujeres desencadena la vía de expresión que lleva a la formación del ovario. Es así como la presencia o ausencia del cromosoma $Y$ durante el establecimiento del sexo cromosómico condiciona al desarrollo testicular u ovárico en la vida fetal.

La tercera etapa corresponde a la diferenciación sexual somática; se refiere a la diferenciación del tracto y los genitales externos. Los fetos que desarrollan testículos, producen dos hormonas que masculinizan el tracto y los genitales externos. Mientras que en los fetos que forman ovarios, la ausencia de hormonas testiculares permite la diferenciación femenina del tracto reproductor y los genitales externos ${ }^{1}$.

Aunque el establecimiento del sexo se inicia en una etapa temprana del desarrollo, los procesos que gobiernan el dimorfismo sexual continúan aún después del nacimiento con el establecimiento del eje hipotálamo-hipófisis-gónada que controla los caracteres sexuales secundarios y directa o indirectamente, el comportamiento sexual y la capacidad reproductiva en los humanos ${ }^{1}$. Los caracteres secundarios se establecen en la pubertad, entre los más llamativos en el sexo masculino se encuentran, el aumento de vello facial, el incremento de masa muscular, ensanchamiento de tórax y hombros, tono de voz grave. Mientras que en el sexo femenino es evidente la aparición de la menarca, la telarca y la disposición de grasa corporal en caderas y muslos.

\section{EstableCIMIENTO DE LA CRESTA GONADAL Y LA GÓNADA INDIFERENCIADA}

Después de la fertilización, continúan los procesos de segmentación, gastrulación y organogénesis. En el caso de los humanos, hacia la quinta semana de gestación se inicia la formación de la cresta gonadal. En embriones de mamífero, el proceso se debe a la proliferación del epitelio celómico en la región ventral del mesonefros (riñón primitivo). La pequeña cresta gonadal está formada por los cordones sexuales primarios derivados del epitelio celómico y el estroma constituido por la invasión de vasos sanguíneos y células mesenquimatosas procedentes de la región mesonéfrica adyacente (Figura 1). Al aumentar de tamaño, la segregación entre el tejido epitelial formado por los cordones sexuales y el tejido estromático es más evidente y alcanza la etapa de gónada morfológicamente indiferenciada o bipotencial, términos que se refieren a la imposibilidad de distinguir el sexo gonadal histológicamente y a que dicho primordio embrionario contiene elementos celulares con capacidad de diferenciarse en células ováricas y testiculares. Además de las células somáticas de los cordones sexuales y el tejido estromático, la cresta genital es colonizada por las células germinales primordiales provenientes del epiblasto (Figura $2 \mathrm{~A}$ ), proceso que ocurre entre la quinta y novena semana de gestación en el humano ${ }^{2}$.

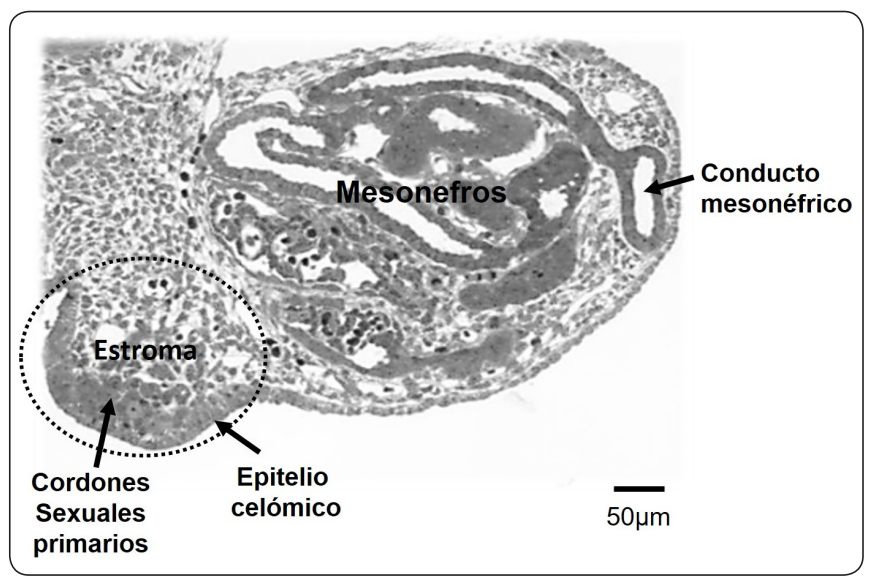

Figura 1. Corte transversal de un complejo urogenital de conejo, formado por la cresta gonadal y el mesonefros. La cresta gonadal (óvalo punteado) la integran el epitelio celómico, los cordones sexuales primarios y el estroma. Este último, es un tejido laxamente organizado que incluye vasos sanguíneos y se continúa hacia el mesonefros adyacente.

\section{La Regulación de la eXPRESIÓn de SRY es neCESARIa PARA EL DESARROLLO TESTICULAR}

En los embriones humanos, transcurren varias semanas en la embriogénesis antes de observar diferencias histológicas y funcionales en las gónadas. Durante este periodo se establece una cascada de expresión molecular que dirigirá el desarrollo ovárico o testicular, a este proceso se le llama determinación sexual gonadal.

A finales de la década de los años cincuenta, se comprobó que la presencia del cromosoma Y era decisivo para la determinación del sexo masculino y con ello apareció la propuesta de la existencia de un factor determinante de testículo (FDT). El cromosoma Y posee una región específica y una región 


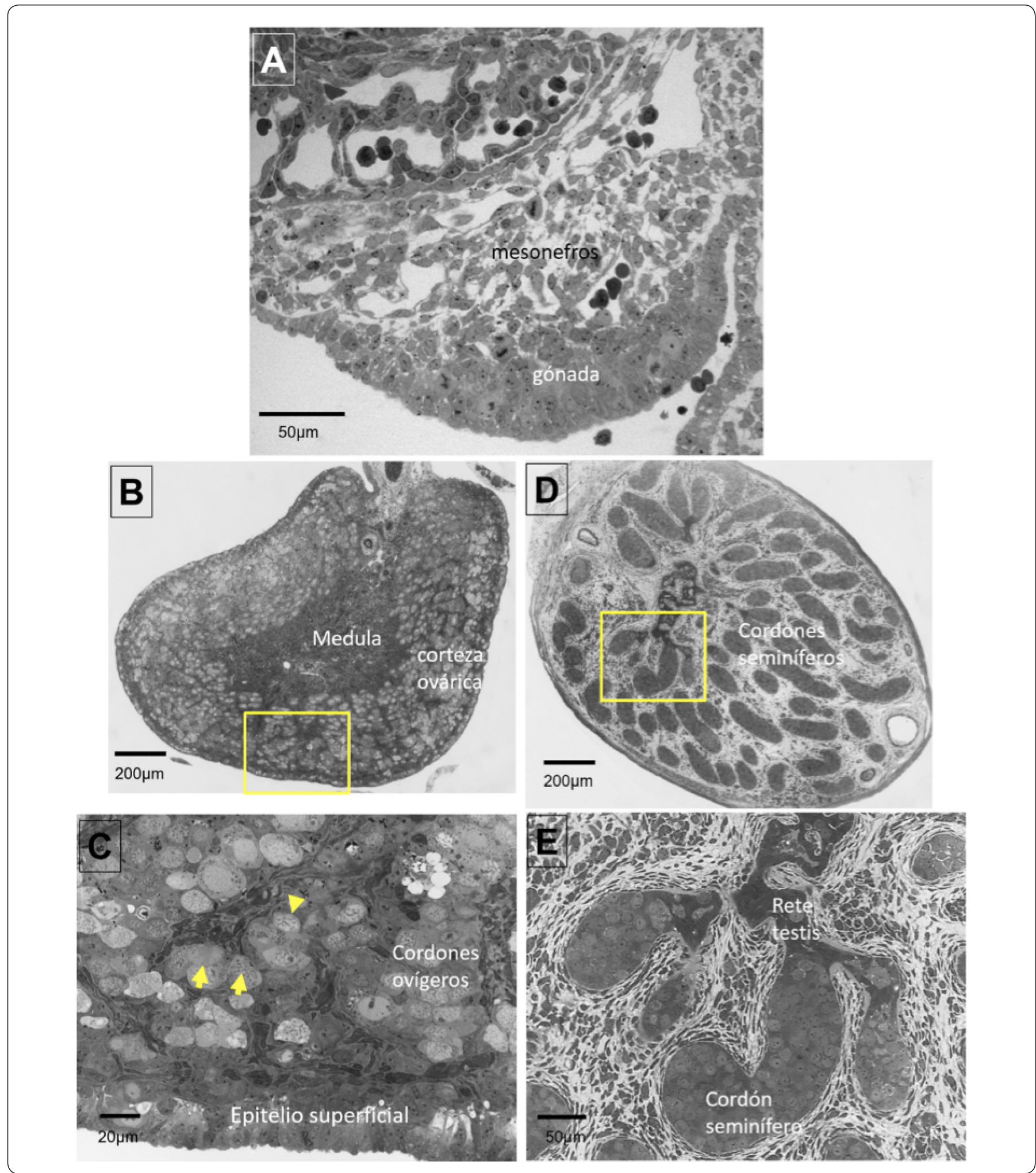

Figura 2. Desarrollo morfológico de las gónadas de conejo. A) Corte transversal de una cresta gonadal morfológicamente indiferenciada. B) Diferenciación morfológica del ovario, se observa la región medular y la corteza ovárica engrosada, en el recuadro amarillo se muestra la amplificación del corte mostrado en el panel C) las flechas señalan ovocitos que han iniciado la meiosis. D) Diferenciación morfológica del testículo fetal, en la región medular se observa la segregación de los cordones seminíferos, en el recuadro amarillo se muestra la amplificación de los cordones seminíferos junto con la rete testis (E). 
pseudoautosómica (PAR 1, por sus siglas en inglés) en la región terminal del brazo corto, que comparte con el cromosoma X. Esta región es requerida para el apareamiento durante la meiosis ${ }^{3}$.

La región PAR1 fue clonada y sirvió para realizar el tamizaje de secuencias para identificar al FDT. En un inicio se encontró al gene $Z F Y$, el cual codifica para un factor de transcripción de la familia dedos de zinc. Su locus y función proteica lo propusieron como un primer candidato FDT. Sin embargo, se identificaron genes homólogos en marsupiales y su patrón de expresión espacio-temporal no correspondió con su esperada función como determinante testicular ${ }^{3}$. Siendo así que en 1990, el gen Sry fue propuesto como candidato para el FDT al identificarse una mutación con reversión sexual en una mujer con contenido cromosómico 46, XY ${ }^{4-6}$. Un año después, Koopman y colaboradores demostraron que el gen $S r y$ es el FDT ${ }^{7}$. El gen Sry se ubica en el brazo corto del cromosoma Y, justo debajo del límite de la región pseudoautosómica. La demostración consistió en la generación de ratones transgénicos XX con una inserción de 14 kilobases del brazo corto del cromosoma Y, que contenía al gen Sry y secuencias reguladoras. Los ratones transgénicos $\mathrm{XX}$ desarrollaron testículos, tracto masculino y pene. Desde entonces la expresión del gen $S r y$ ha sido ampliamente estudiada en varias especies, colocándolo como el gen maestro de la determinación sexual en mamíferos.

El gen Sry (Sex Determining Region of the Y Chromosome) codifica para un factor de trascripción del mismo nombre que se caracteriza por unirse a secuencias de ADN blanco y modificar la expresión génica. La expresión del gen Sry en las células precursoras de Sertoli de los cordones seminíferos en la gónada humana inicia entre los días 41 y 44 post-ovulación ${ }^{8}$. Pocas horas después, las mismas células expresan al gen Sox 9 (Sex determining región Y-box9) ${ }^{9}$ A diferencia del gen Sry, es un gen autosómico ubicado en el cromosoma 17 en humanos y su expresión es requerida en otros eventos del desarrollo embrionario por ejemplo en la condrogénesis. En la Figura 3A-B se muestran fotografías de hibridación in situ donde se detectaron los transcritos de Sox9 en muestras de conejo. Su expresión se observa tanto en las costillas como en las crestas genitales, evidenciándose su expresión pleiotrópica.

\section{Sox9 el Gen blanco de Sry: el control molecular DE LA DETERMINACIÓN SEXUAL}

El mejor modelo experimental para elucidar los mecanismos involucrados en la determinación y diferenciación sexual ha sido el ratón. Sabemos que Sry como factor de transcripción tiene como blanco a Sox 9. El factor de transcripción Sry junto con el factor esteroidogénico1 (SF1) se unen directamente a un enhancer (potenciador), testículo-específico denominado TESCO (Testis-Specific Core) de $\operatorname{Sox} 9$ y con ello contribuyen a incrementar los niveles de este gen ${ }^{10}$. A su vez, $\operatorname{Sox} 9$ es capaz de unirse a su propio enhancer manteniendo así su propia expresión. Sox 9 también mantiene un proceso de regulación positiva con el factor de crecimiento fibroblástico 9 (FGF9) y la enzima prostaglandina sintasa D2 (PGD2) ${ }^{11}$. Con ellos, los niveles de $\operatorname{Sox} 9$ se mantienen en el testículo diferenciado, ya que el periodo de máxima expresión de $S r y$ durante la vida fetal es muy corto.

Las primeras evidencias de la función de $\operatorname{Sry}$ y $\operatorname{Sox} 9$ sobre la determinación sexual fueron descubiertas en humano,

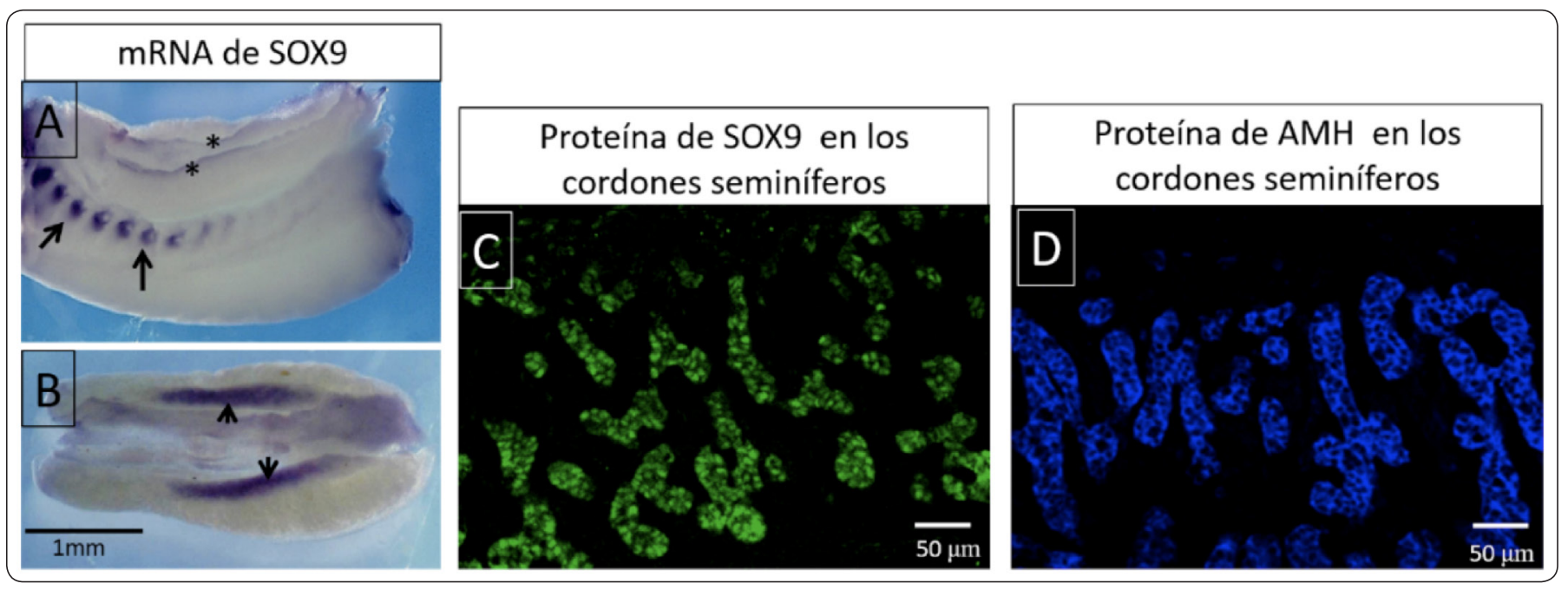

Figura 3. Expresión de Sox9 y hormona antimülleriana A y B) Preparación de hibridación in situ de muestras completas de conejo, se observa la expresión localizada de ARNm de Sox9 (morado), en A se señala la expresión de Sox9 en las costillas (flechas) y en las crestas gonadales (asteriscos). B) Se observa una intensa expresión de Sox9 en las gónadas XY (flechas) C) Inmunofluorescencia para detectar la expresión de la proteína SOX9 (verde) en los cordones seminíferos de un testículo fetal de conejo. D) Se muestra la inmunofuorescencia para identificar la expresión de la hormona antimülleriana en los cordones seminíferos de un testículo de conejo fetal. 
donde mutaciones heterocigotas de Sox9 llevan a una haploinsuficiencia ${ }^{12}$. En consecuencia, se induce el síndrome de displasia campomélica que en muchos casos incluye la reversión sexual en pacientes XY. A su vez, otros estudios demostraron que la sobreexpresión de Sox9 en individuos XX lleva a la reversión sexual donde individuos XX desarrollan un testículo y la consecuente masculinización fenotípica. Como la expresión de Sox 9 regula directamente la expresión de la hormona antimülleriana. En la Figura $3 \mathrm{C}$ se muestran inmunotinciones para Sox 9 en un testículo de conejo, mientras que en un corte alternado de la misma muestra (Figura 3D) se muestra la inmunolocalización de la hormona antimülleriana. En el caso de pacientes con haploinsuficiencia de $\operatorname{Sox} 9$ desarrollan un tracto genital femenino.

En los años 90 el producto del gen $\operatorname{Dax} 1$ (Dosage-sensitive sex reversal, adrenal hipoplasia critical region on the Chromosome, gene 1), también conocido como NROB1 se postuló como un factor "anti-testículo", basado en el hallazgo de pacientes XY con una duplicación Xp21 con reversión sexual y su expresión dimórfica entre ovarios y testículos ${ }^{13-16}$. Sin embargo, el ratón knockout presentó degeneración de los cordones seminíferos con la pérdida completa de las células germinales, por lo que los ratones son azoospérmicos ${ }^{17}$. De manera similar, se han identificado pacientes con azoospermia secretora que presentan alguna mutación en $\operatorname{Dax}^{18-20}$. Recientemente, Ludbrook y colaboradores (2012), reportaron una estrategia experimental para determinar como la doble dosis de Dax1 lleva a la reversión sexual en ratones. El exceso de proteína DAX1 reduce la activación del enhancer de Sox9 al inhibir la interacción de Sf1 con Wt1. Antagonizando así el proceso esteroidogénico y la producción de hormona antimülleriana ${ }^{21}$. El modelo animal dio una respuesta a la interrogante de cómo la doble dosis de Daxl lleva a la reversión sexual en humanos. No obstante, queda por elucidarse el tipo de interacciones proteína-proteína que se llevan a cabo durante el proceso de determinación sexual gonadal.

Si bien, el objetivo de este artículo es abordar el proceso de determinación sexual del testículo a partir de la expresión de los genes maestros Sry y Sox 9, las redes de expresión involucradas en el establecimiento de un ovario o un testículo incluyen muchos otros genes. Una revisión actualizada al respecto, puede ser consultada en: Svingen y Koppman (2013) ${ }^{22}$, así como en Windley y Wilhelm $(2015)^{23}$.

\section{De la determinación a la diferenciación sexual del TESTÍCULO}

Si bien, hemos mencionado que Sry y Sox 9 son los genes maestros para la determinación sexual de la gónada indiferenciada, ahora revisaremos los cambios morfológicos que controlan la diferenciación estructural del testículo.

Hacia finales de la sexta semana de gestación en humanos, la expresión de Sry y Sox 9 en las células precursoras de Sertoli promueve los siguientes eventos:

1. Formación de los cordones seminíferos: Los cordones sexuales primarios incrementan su tamaño, se separan del epitelio celómico por una densa capa de tejido conectivo llamada túnica albugínea y se transforman en cordones seminíferos, precursores de los túbulos seminíferos. La porción de cordones seminíferos que se mantiene unida a los túbulos mesonéfricos se transforman en la rete testis (Figura 2D-E). Mientras que los túbulos mesonéfricos forman los conductos eferentes Los cordones seminíferos son evidentes en todo el testículo humano después de las seis semanas de gestación ${ }^{24}$.

2. Diferenciación de las células de Sertoli: La formación de los túbulos seminíferos es precedida por la diferenciación ultraestructural de las células de Sertoli caracterizadas por tener un citoplasma abundante, retículo endoplásmico rugoso, zonas de contacto con repliegues e interdigitaciones de las membranas y una capa de microfilamentos por debajo de la superficie aplanada de las células ${ }^{25}$.

3. Formación de la lámina basal de los cordones testiculares: Las células de Sertoli se agregan junto con las células germinales formando los cordones seminíferos envueltos por una lámina basal secretada por las células de Sertoli. Una vez creada esta lámina, las células germinales primordiales no podrán ingresar ni ser parte del cordón testicular.

4. Incremento de la vasculatura: La expresión de $S r y$ y $\operatorname{Sox} 9$ promueve la invasión de abundantes vasos sanguíneos provenientes de la región mesonéfrica adyacente, hacia la gónada. Grandes vasos sanguíneos se desplazan por debajo del epitelio celómico y transcurren a lo largo del testículo en la región opuesta al mesonefros. De hecho, la formación de los vasos sanguíneos es uno de los eventos tempranos que marca la diferenciación morfológica del testículo que permite distinguir al testículo fetal a simple vista. Además, el proceso de angiogénesis que implica la migración y proliferación de células endoteliales del mesonefros hacia la gónada, es un requisito para la segregación de los cordones seminíferos, ya que, si se inhibe la angiogénesis, los cordones testiculares no se forman ${ }^{26,27}$.

5. Inducción de la diferenciación de las células de Leydig: Las células de Sertoli inducen la diferenciación del principal tipo celular en el estroma, es decir, las células de Leydig que son las productoras de andrógenos.

6. Síntesis de hormona antimülleriana: Las células de Sertoli comienzan a expresar a la hormona antimülleriana, clave para inducir la regresión de los conductos müllerianos (precursores del tracto genital femenino: trompas de Falopio, útero y parte superior de la vagina) presentes aún en el embrión en desarrollo. La regresión de los conductos de Müller es el primer signo de diferenciación del tracto genital masculino y ocurre en embriones de 55 a 60 días de gestación ${ }^{2}$. 


\section{LA DIFERENCIACIÓN DE LAS CÉLULAS DE LEYDIG}

Las células de Leydig fetales se observan en el intersticio, hacia la octava semana de gestación, y se mantienen hasta el nacimiento ${ }^{28}$. Durante la vida fetal, la producción de andrógenos, específicamente de testosterona, es necesaria tanto para la diferenciación de los conductos de Wolff en conductos deferentes y vesículas seminales como para la transformación del mesonefros en epidídimo y la masculinización de los genitales externos. Las células de Leydig también producen el factor parecido a relaxina 3 (Insl3), requerido para el descenso transabdominal del testículo ${ }^{29}$.

El origen de las células de Leydig es controversial. Algunos autores proponen que se originan del epitelio celómico ${ }^{30}$, mientras otros autores sugieren que se desarrollan a partir de células mesenquimatosas que se encuentran entre la unión de la cresta gonadal con el mesonefros y que paulatinamente invaden la cresta en desarrollo ${ }^{31}$. Recientes estudios sobre las células de Leydig apoyan que tanto el epitelio celómico como las células que migran desde el mesonefros contribuyen con células precursoras de Leydig ${ }^{31-32}$. Recientemente Zhang y colaboradores (2015), reprogramaron células de Sertoli derivadas de ratones transgénicos (Knockout de WT1) capaces de transdiferenciarse en células de Leydig $^{33}$. Sin embargo, aún no se sabe si dicho experimento puede ser reproducido en células de Sertoli humanas.

Las células de Sertoli recién diferenciadas expresan al factor de señalización Desert Hedgehog (Dhh) y Fgf9 importantes para la diferenciación de las células de Leydig ${ }^{34-35}$. Existen tres vías de señalización para la diferenciación de las células de Leydig. En el ratón, Dhh se une a su receptor patched 1 (Ptch1) en células mesenquimatosas del intersticio gonadal ${ }^{36}$. A continuación, las células precursoras de Leydig expresan SF1 que es requerido para la activación de genes implicados en la esteroidogénesis como son Cyp11a, Scc y la proteína StAR $^{36}$.

\section{LA IMPORTANCIA DE LAS HORMONAS DEL TESTÍCULO FETAL EN LA DIFERENCIACIÓN SEXUAL}

Aproximadamente a las nueve semanas de gestación el tracto genital, el seno urogenital y los genitales externos permanecen indiferenciados ${ }^{2}$. El seno urogenital es una estructura embrionaria derivada del endodermo que contribuye con la formación del tracto reproductor y la uretra en ambos sexos. Al inicio del desarrollo el seno urogenital se encuentra unido al recto y en conjunto forman a la cloaca. Hacia la quinta semana de gestación, el recto se separa del seno urogenital gracias a la formación de los tabiques urorectales. En el sexo masculino el seno urogenital contribuye con la formación de la próstata y la uretra. El establecimiento de la diferenciación sexual del tracto y genitales externos masculinos depende de la producción de dos hormonas producidas por el testículo fetal: la testosterona y la hormona antimülleriana. Mientras que la ausencia de estas dos hormonas lleva a la feminización del tracto y genitales externos, independientemente de la existencia o ausencia de los ovarios. Es por ello que se considera que la diferenciación del fenotipo femenino es constitutiva, sin embargo, es un proceso que requiere de la expresión coordinada de genes no iniciada por hormonas gonadales.

La hormona antimülleriana, también llamada sustancia inhibidora de los conductos de Müller, induce la regresión de los conductos müllerianos, precursores del útero, las trompas de Falopio y tercio superior de la vagina. Por otra parte, la acción de la testosterona fetal hace que los conductos de Wolff se transformen en conductos deferentes y vesículas seminales, además, llevan a la transformación del mesonefros en epidídimo.

En fetos de hembras XX con ovarios e incluso en fetos machos $\mathrm{XY}$ sin gónadas, al no producirse la hormona antimülleriana, los conductos de Müller inician su diferenciación formando trompas de Falopio, útero y el componente superior de la vagina. El seno urogenital contribuye con la diferenciación de los dos tercios inferiores de la vagina. Por otra parte, la ausencia de andrógenos lleva a la regresión de los conductos de Wolff, de esta manera el tracto y los genitales externos son feminizados. Sin embargo, al llegar a la pubertad, tanto el tracto como los genitales externos son sensibles a las hormonas esteroides producidas por las gónadas. Por ello, si un individuo con agenesia gonadal desarrolla un fenotipo femenino, no será capaz de llegar a la madurez sexual. La Figura 4 presenta un diagrama de flujo donde se resumen los eventos de determinación y diferenciación masculina.

\section{LA DIFERENCIACIÓN DE LOS GENITALES EXTERNOS}

Los genitales externos también atraviesan un periodo indiferenciado, alrededor del orificio cloacal se desarrollan 3 formaciones conocidas como tubérculo genital, pliegue cloacal y eminencias genitales.

Los genitales externos también requieren de la acción hormonal de los andrógenos secretados por las células de Leydig. La testosterona producida por el testículo fetal es transformada a dihidrotestorena (andrógeno más potente por su mayor afinidad al receptor) por acción de la enzima 5 alfa reductasa. Así, a partir del tubérculo genital, la dihidrotestosterona, induce la formación de la cabeza del pene, los pliegues cloacales se fusionan contribuyendo con la formación del falo el rafe uretral. Mientras que las tumefacciones genitales se unen y forman las bolsas escrotales ${ }^{37}$ (Figura 5).

En el caso de los embriones del sexo femenino el tubérculo genital da origen al clítoris, los pliegues cloacales no se fusionan y originan a los labios menores, y las eminencias genitales se mantienen separadas originando los labios mayores $^{37}$ (Figura 5). 


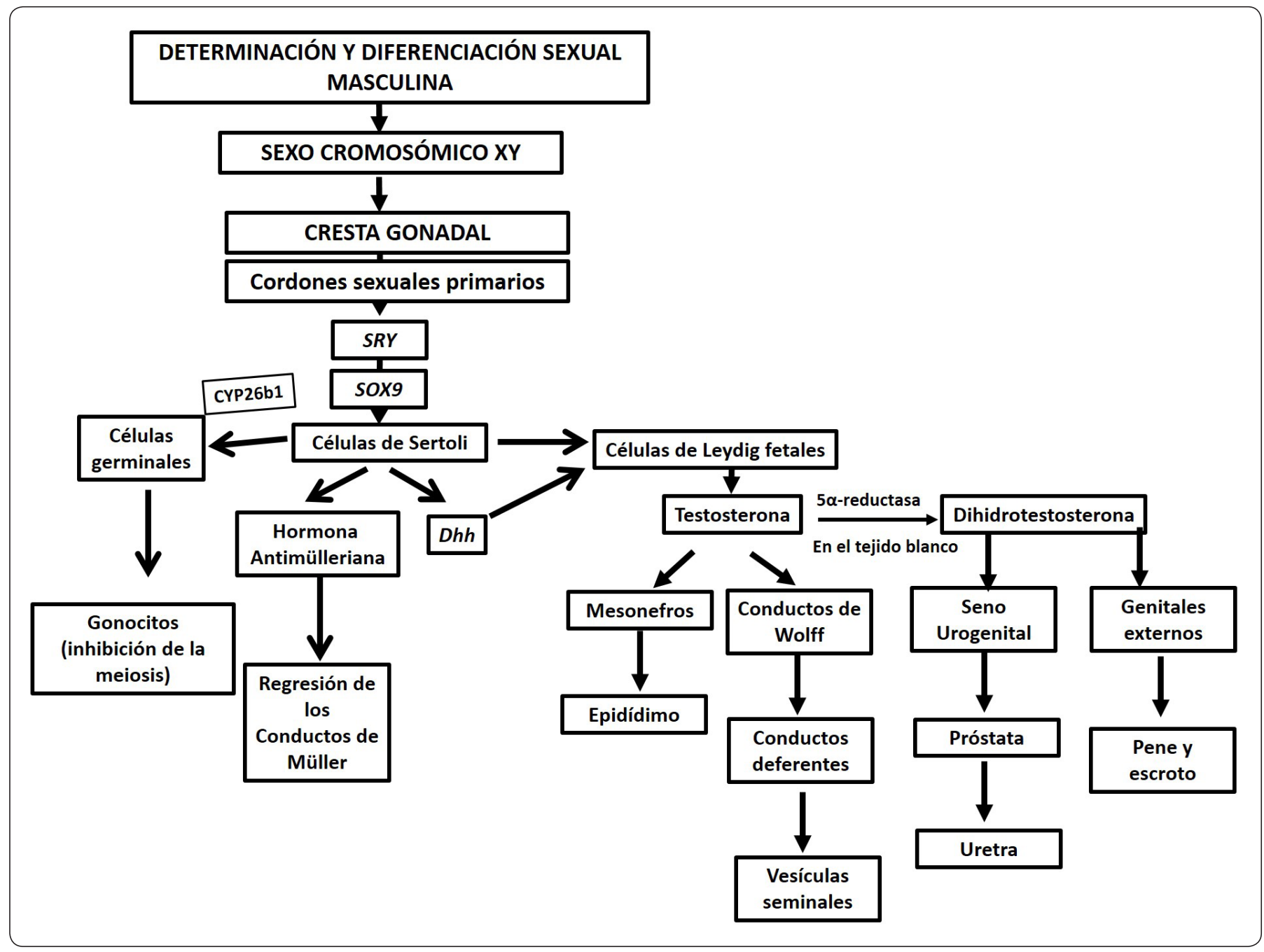

Figura 4. Diagrama de flujo del establecimiento del sexo masculino. En el diagrama de flujo se resumen los eventos moleculares que llevan a la masculinización fenotípica en mamíferos. En individuos con una dotación cromosómica XY la diferenciación de la cresta gonadal hacia el testículo es inducida por la expresión de los genes Sry y Sox9. La diferenciación fenotípica masculina depende de un mecanismo hormonal. Las células de Sertoli producen a la hormona antimülleriana encargada de la regresión de los conductos müllerianos. En tanto que las células de Leydig fetales producen testosterona encargada de masculinizar el tracto. La diferenciación del seno urogenital y los genitales externos requieren de la conversión de testosterona en dihidrotestosterona (DHT). Las células germinales primordiales comienzan un proceso de arresto mitótico e inhibición del inicio de la meiosis que las mantiene latentes, como gonocito hasta la pubertad, cuando se reinicia el proceso de espermatogénesis.

\section{LA DETERMINACIÓN SEXUAL DEL OVARIO}

Hasta el momento no se conocen con precisión los mecanismos moleculares mediante los cuales el ovario inicia su proceso de determinación. En un principio se postuló que la determinación del ovario requería la existencia de un "organizador ovárico" ubicado en el cromosoma $X$, por lo que la doble dosis de este gen contribuiría con la determinación ovárica ${ }^{38}$. Otra propuesta de determinación ovárica radicó en inhibir la vía de determinación testicular ${ }^{39}$. Hasta el momento no hay evidencia del factor determinante del ovario y las investigaciones de los últimos veinte años se encaminan hacia la existencia de la inhibición de la determinación testicular.
Entre los genes involucrados en el proceso de determinación y diferenciación del ovario encontramos a Wnt4 y R-sponding, factores de señalización requeridos en el desarrollo de los ovarios $^{40-41}$. La expresión de estos genes podría estar funcionando en conjunto para inhibir la diferenciación testicular ya que Wnt4 inhibe la expresión de $F g f 9$, que como se mencionó con anterioridad regula positivamente la expresión de Sox9.

El gen Foxl2 codifica para un factor de transcripción que es necesario para el mantenimiento de la diferenciación de las células de la granulosa en el ovario ${ }^{42}$. La deleción de Dmrt1 o Sox9 en las células de Sertoli de ratones adultos XY lleva a la 


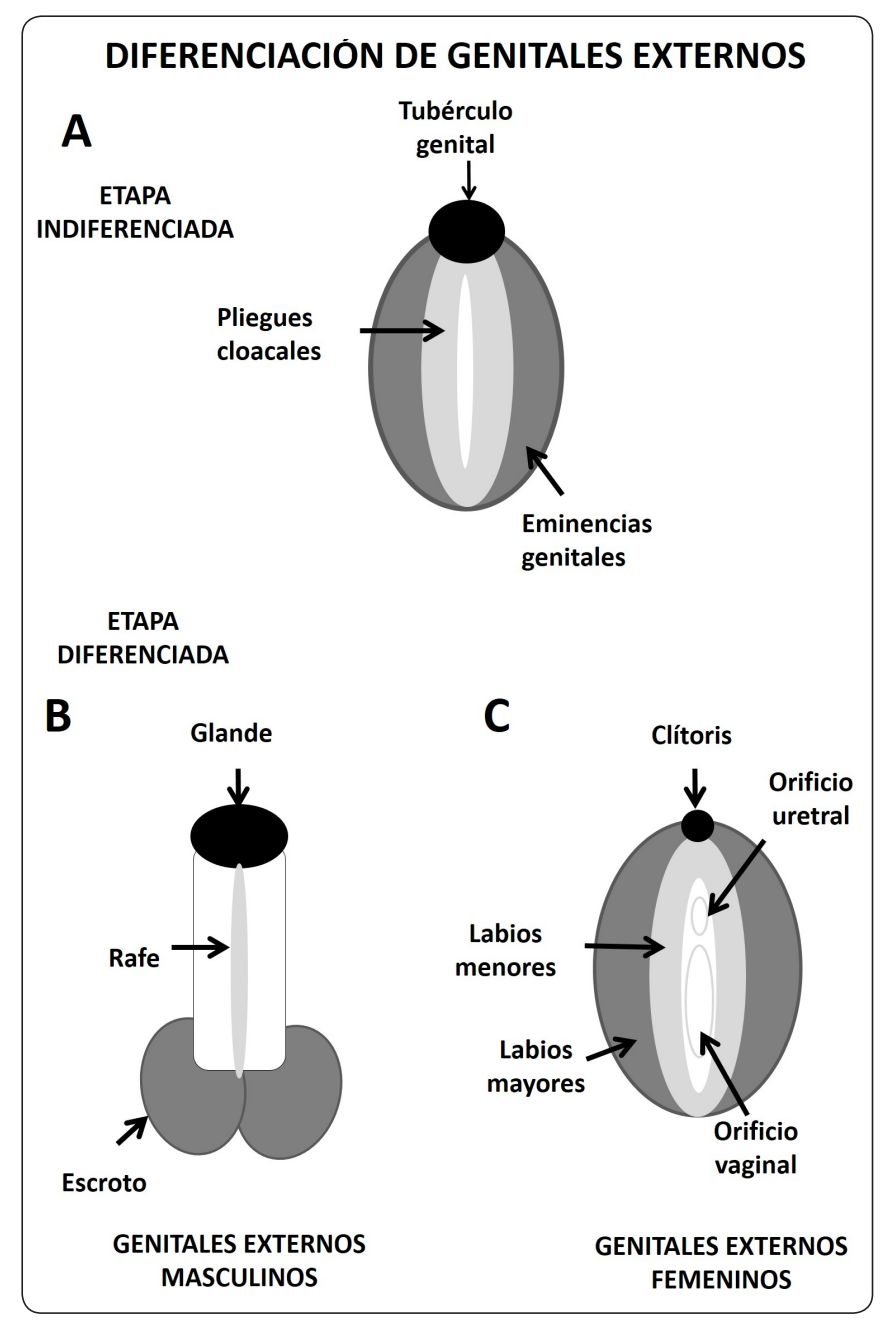

Figura 5. Diagrama de flujo de la determinación y diferenciación sexual femenina. En individuos $X X$, la conversión de la cresta gonadal a ovario requiere de la expresión de genes que inhiban la expresión de Sox9. Entre los más notables se encuentran Foxl2, Wnt4 y Rspo1. El establecimiento del fenotipo femenino no requiere de la producción hormonal ovárica, ya que incluso en ausencia de una gónada se desarrolla un fenotipo femenino. Sin embargo, no se establecen los caracteres sexuales secundarios por la ausencia de los esteroides sexuales. La regresión de los conductos de Wolff se debe a la ausencia de testosterona, mientras que la ausencia de la hormona antimülleriana permite la diferenciación de las trompas de Falopio, el útero y la porción superior de la vagina.

expresión de Foxl2 y a la transdiferenciación de las células de Sertoli en células de la granulosa ${ }^{43-44}$. Asimismo, la deleción de Foxl2 en ovarios de ratones hembra púberes lleva a que folículos antrales adquieran características semejantes a túbulos seminíferos y las células expresan marcadores que caracterizan a las células de Sertoli ${ }^{44}$. Este mismo fenotipo es obtenido en las gónadas de ratones cuya expresión de los receptores a estrógenos ha sido eliminada ${ }^{44-46}$. Estos trabajos sugieren que Foxl2 actúa sinérgicamente con los receptores a estrógenos para inhibir la expresión de SOX9 en el testículo adulto.

Las evidencias recientes sugieren que la determinación ovárica requiere de la inhibición de la vía de señalización del testículo teniendo como blanco la inhibición de Sox9. Es muy sorprendente que durante el desarrollo embrionario temprano R-sponding1 y Wnt4 actúan inhibiendo a Sox9, mientras que en el ovario adulto la inhibición depende de Foxl2 y de los receptores a estrógenos (Figura 6).

\section{LA DIFERENCIACIÓN DEL OVARIO}

La diferenciación sexual del ovario es un proceso que se hace evidente muy tarde en la vida fetal, por lo que mantiene un estado indiferenciado por más tiempo. La mayor parte de los cordones sexuales primarios degeneran y sólo quedan algunos remanentes que forman la rete ovarii. En contraste con las gónadas XY, el epitelio celómico de las XX continúa proliferando y origina un segundo grupo de cordones denominados cordones ovígeros que forman la corteza del ovario. Estos cordones están formados por las somáticas epiteliales precursoras de las células de la granulosa y la mayor parte del volumen de los cordones ovígeros es ocupada por las células germinales (Figura 2B-C).

Las células germinales en el ovario fetal se mantienen proliferando hasta cerca del tercer mes de gestación y reciben el nombre de ovogonias. Hacia el tercer mes de gestación, inician la profase I de la meiosis y se diferencian como ovocitos ${ }^{47}$. El proceso de foliculogénesis fetal se inicia a partir de la fragmentación de los cordones ovígeros ${ }^{48-49}$.

Los folículos mantienen su identidad epitelial al conservar la lámina basal de los cordones epiteliales que los separa del tejido estromático. El estroma ovárico está formado por células mesenquimáticas, fibroblastos, vasos sanguíneos, células precursoras de las tecas interna (esteroidogénica) y externa (tejido conectivo) $^{50}$.

Los ovocitos rodeados de células epiteliales planas se conocen con el nombre de folículos primordiales, en tanto que los ovocitos rodeados por células cúbicas reciben el nombre de folículos primarios.

Mientras el número de células de la granulosa aumenta, se inicia la diferenciación de las células esteroidogénicas de la teca interna. Los folículos primordiales crecen hasta la formación de los folículos secundarios caracterizados por la presencia del antro, el cual se encuentra lleno de licor folicular. El crecimiento de los folículos primordiales hasta la fase de folículos secundarios preantrales requiere de una regulación intraovárica, independiente del eje hipotálamo-hipófisis-ovario ${ }^{47,51}$. La Figura 6 presenta un diagrama de flujo donde se resumen los eventos de determinación y diferenciación femenina. 


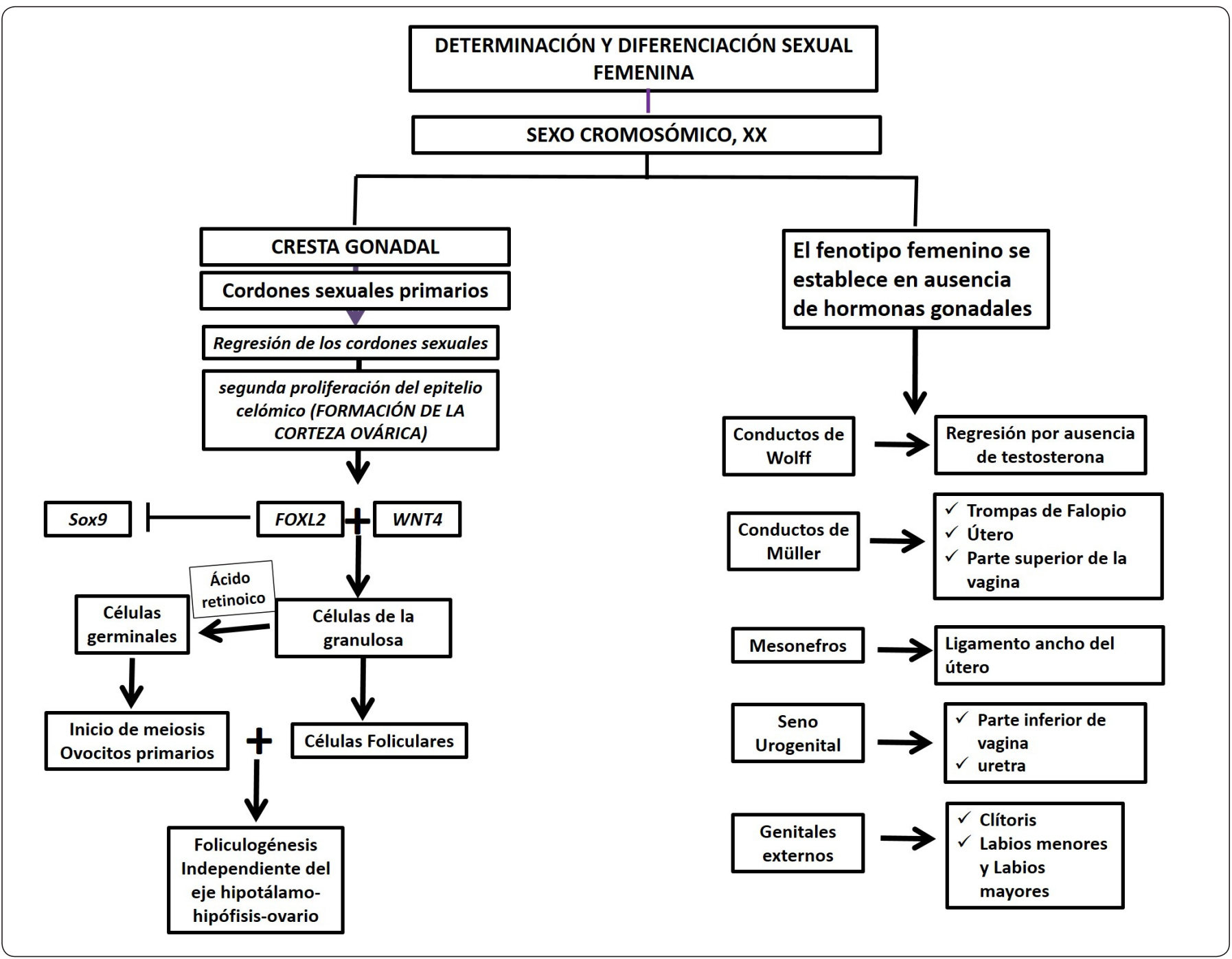

Figura 6. Esquema de diferenciación de los genitales externos. A. Fase indiferenciada de los genitales externos, aproximadamente a las 4 semanas de gestación en humano. B. Desarrollo de los genitales externos en el varón, al nacimiento. El tubérculo genital crece y origina el falo, los pliegues cloacales se fusionan para dar origen a la uretra, las eminencias genitales se fusionan y originan el escroto. C. Formación de los genitales externos femeninos. El tubérculo genital aparenta una reducción de tamaño y da origen al clítoris. Los pliegues cloacales crecen para originar los labios menores, mientras que las eminencias genitales forman los labios mayores.

Al llegar a la pubertad, el crecimiento y maduración de los folículos antrales tempranos dependerá en gran medida del estímulo de la hormona folículo estimulante secretada por la adenohipófisis. A partir de la reserva folicular establecida en la vida fetal, la reserva folicular total del ovario decrece gradual y progresivamente. La duración de la función del ovario está en directa relación con el número de folículos presentes en la reserva folicular la cual se considera que en mamíferos es no renovable ${ }^{52}$. Sin embargo, en últimas fechas se ha reportado la existencia de células troncales germinales en el ovario de animales en etapa reproductiva ${ }^{53}$ aunque los resultados no son convincentes para la mayoría de los investigadores ${ }^{54}$.

\section{El papel del ÁCIDO REtinOICO EN LA DIFERENCIACIÓN DE LAS CÉLULAS GERMINALES}

Las células germinales primordiales migran hacia la cresta gonadal a finales de la quinta semana de gestación ${ }^{2}$, durante su trayecto aumentan en número gracias a varias divisiones mitóticas. Durante este periodo y pocas semanas después de llegar a la gónada son bipotenciales, es decir, que sin importar su sexo cromosómico podrían originar ovocitos o espermatozoides.

Si las células germinales llegan al ovario, continúan con varias rondas proliferativas para dar origen a las ovogonias, que iniciarán la meiosis alrededor del tercer mes de gestación. 
Trabajos recientes en ratón mostraron que el ácido retinoico, un derivado de la vitamina A producido por el mesonefros adyacente, ingresa al ovario e induce la expresión del gen Stra8 (Stimulated by retinoic acid 8). La expresión de Stra 8 es crítica para la condensación de los cromosomas meióticos ${ }^{55-56}$.

En el testículo fetal, las células germinales en los cordones seminíferos detienen gradualmente su comportamiento proliferativo y entran en un proceso de detención mitótica (16-18 semanas de gestación) y de inhibición meiótica. En este periodo las células germinales ahora reciben el nombre de gonocitos ${ }^{57}$. Estudios recientes en el ratón mostraron que los gonocitos no inician la meiosis porque las células de Sertoli producen la enzima Cyp26b1 encargada de metabolizar el ácido retinoico proveniente del mesonefros adyacente ${ }^{56}$.

Hasta el momento, se ha reportado que en los ovarios humanos el ácido retinoico es producido por el propio ovario, pero poco se ha avanzado en esclarecer si el mecanismo que controla la meiosis en las gónadas de ratón es igual en la gónada humana. Por lo que aún está por demostrarse si la acción del ácido retinoico es el único efector capaz de iniciar el proceso meiótico en las gónadas fetales.

\section{Desórdenes del deSARRollo SEXUAL}

Los desórdenes del desarrollo sexual (DSD) son una serie de alteraciones congénitas detectables a nivel de los cromosomas sexuales, del desarrollo gonadal, del tracto genital, así como en los genitales externos. Según la declaración del consenso sobre la gestión de los desórdenes intersexuales (Consensus Statement on Management of Intersex Disorders) realizado en 2006, los desórdenes del desarrollo sexual se clasifican en tres grupos ${ }^{58}$ :

1) Desorden del desarrollo sexual 46, XY,

2) Desorden del desarrollo sexual $46, \mathrm{XX}$;

3) Desorden del desarrollo sexual de cromosomas sexuales.

Esta nueva clasificación, sustituye a los términos pseudohermafroditismo masculino, pseudohermafroditismo femenino, hermafrodita verdadero, mientras que el término desórdenes del desarrollo sexual nulifica el término intersexo y reversión sexual. El consenso determinó la eliminación de dichos términos por considerarlos confusos, despectivos y peyorativos hacia los pacientes.

Los desórdenes del desarrollo sexual suelen ser resultado de anomalías en los cromosomas sexuales, durante la diferenciación sexual de la gónada, en la producción de testosterona y hormona antimülleriana e incluso de los receptores de estas hormonas en sus órganos blanco. Las patologías de la diferenciación sexual pueden abarcar la ambigüedad de los genitales externos, es decir que no se encuentre definido de manera clara el tipo de genitales externos o bien que el tipo de genitales externos no correspondan al sexo genético y gonadal.
Los desórdenes en el desarrollo de cromosomas sexuales son debidos a alteraciones cromosómicas pero no a una disyunción meiótica o mitótica, por ejemplo, mosaicismo cromosómico (XY/XX). Los pacientes con esta alteración desarrollan ovotestis, formadas por tejido ovárico en la periferia de la gónada y tejido testicular en la región medular o bien pueden presentar un ovario y un testículo en posición contralateral $\mathrm{u}$ ovotestis y un ovario o testículo contralateral. La combinación gonadal presente en el paciente dependerá del número de células XX o $\mathrm{XY}$ que formaron la gónada durante el desarrollo. Con respecto a la determinación del sexo somático el paciente desarrolla un tracto y genitales externos ambiguos.

En los desórdenes 46, XX o 46, XY, los genitales externos no corresponden al sexo cromosómico. Pacientes con un Desorden del Desarrollo Sexual 46, XX presentan un sexo cromosómico $\mathrm{XX}$ y genitales externos masculinos, el sexo gonadal corresponde al cromosómico, es decir, desarrollan ovarios. Este tipo de alteraciones ocurren frecuentemente por fallas en la producción hormonal o defectos en los receptores de éstas. Por ejemplo, la hiperplasia suprarrenal congénita es una patología donde las glándulas suprarrenales producen un exceso de andrógenos, si esta alteración está presente en un feto 46, XX provoca que el tracto y genitales externos se masculinicen. El grado de masculinización dependerá de la etapa del desarrollo fetal en la que los andrógenos fueron producidos ${ }^{58}$.

El Desorden del Desarrollo Sexual 46, XY corresponde a pacientes con una dotación cromosómica 46XY y desarrollan testículos. Sin embargo, los genitales externos adquieren un fenotipo femenino. Un ejemplo de esta patología es el síndrome de insensibilidad completa a andrógenos. Durante el desarrollo temprano, los pacientes XY desarrollan testículos y estos son capaces de producir hormona antimüllerina y testosterona. No obstante, una mutación que inactiva la función de los receptores a andrógenos evita la masculinización de los genitales externos. Los testículos no descienden y desarrollan una vagina en saco ciego. En estos pacientes, la hormona antimülleriana producida por las células de Sertoli induce la regresión de los conductos Müllerianos, por lo que no desarrollan útero, ni tampoco trompas de Falopio. El fenotipo de estos pacientes es muy semejante al desarrollado en individuos con deficiencia de la enzima 17 $\beta$-hidroxiesteroide deshidrogenasa, que realiza la biotransformación de androstenediona a testosterona. Estos pacientes también desarrollan un fenotipo femenino en presencia de un cariotipo 46, XY. Por lo general, los pacientes asisten a consulta por problemas como amenorrea o infertilidad ${ }^{58}$.

\section{Conclusiones}

El establecimiento del sexo en mamíferos requiere de tres eventos de determinación secuenciales: (1) sexo cromosómico, (2) sexo gonadal y (3) sexo fenotípico. La alteración a cualquiera de los tres niveles puede llevar a una alteración del desarrollo sexual, como las expuestas en este trabajo. El hallazgo de mutaciones, 
deleciones o translocaciones, en genes clave de la cascada molecular que lleva al desarrollo de un ovario o testículo, ha permitido avanzar cada vez más en los mecanismos que nos llevan a establecer el sexo en la gónada. Aún hay mucho por entender acerca de la determinación ovárica y el establecimiento del fenotipo femenino, y en especial sobre el mantenimiento de su diferenciación ovárica, ya que alteraciones en los niveles de expresión de genes implicados en promover la función de las células somáticas o el número de células germinales podría llevar a alteraciones como son la falla ovárica temprana y el síndrome de ovario poliquístico, entre otros. Es por ello que entender los mecanismos conducentes a la determinación y diferenciación sexual gonadal podrían ser importantes para comprender patologías que no necesariamente llevan a un proceso de reversión sexual.

\section{AgradeCIMIENTOS}

Agradecemos el apoyo técnico del M.C. Alejandro Marmolejo Valencia. Este trabajo se realizó con el financiamiento PAPIITUNAM IN216717, IN202115 y CONACyT 166012.

\section{Referencias}

1. Jost, A., Price, D. \& Edwards, R.G. Hormonal factors in the sex differentiation of the mammalian foetus. Philos. Trans. R. Sox. Lond. B Biol. Sci. 259, 119-130 (1970).

2. Rey, R., Josso, N. \& Racine, C. (eds. L.J. De Groot, G. Chrousos, \& K. Dunkan) (Endotext (Internet), 2016).

3. Harley, V.R. \& Goodfellow, P.N. The biochemical role of SRY in sex determination. Mol. Reprod. Dev. 39, 184-193 (1994). DOI: 10.1002/mrd.1080390211.

4. Berta, P., Hawkins, J.R., Sinclair, A.H., Taylor, A., Griffiths, B.L., Goodfellow, P.N. \& Fellous, M. Genetic evidence equating SRY and the testis-determining factor. Nature 348, 448-450 (1990). DOI: 10.1038/348448A0.

5. Sinclair, A.H., Berta, P., Palmer, M.S., Hawkins, J.R., Griffiths, B.L., Smith, M.J., Foster, J.W., Frischauf, A.M., Lovell-Badge, R. \& Goodfellow, P.N. A gene from the human sex-determining region encodes a protein with homology to a conserved DNAbinding motif. Nature 346, 240-244 (1990).

6. Jager, R.J.,Anvret, M., Hall, K. \& Scherer, G. Ahuman XY female with a frame shift mutation in the candidate testis-determining gene SRY. Nature 348, 452-454 (1990).

7. Koopman, P., Gubbay, J., Vivian, N. \& Goodfellow, P. Male development of chromosomally female mice transgenic for Sry. Nature. 351,117-121 (1991).

8. Hanley, N.A., Hagan, D.M., Clement-Jones, M., Ballc, S.G., Strachan, T., Salas-Cortés, L., McElreavey, K., Lindsay, S., Robson, S., Bullen, P., Ostrer, H. \& Wilson, D.I. SRY, SOX9, and DAX1 expression patterns during human sex determination and gonadal development. Mechanisms of Development 91,403407. (2000).

9. Sekido, R., Bar, I., Narvaéz, V., Penny, G. \& Lovell-Badge, R. SOX9 is up-regulated by the transient expression of SRY specifically in Sertoli cell precursors. Developmental Biology
274, 271-279 (2004).

10. Sekido, R. \& Lovell-Badge, R. Sex determination involves synergistic action of SRY and SF1 on a specific Sox 9 enhancer. Nature 453, 930-934 (2008).

11. Wilhelm, D., Martinson, F., Bradford, S., Wilson, M.J, Combes, A.N., Beverdam, A., Bowles, J., Mizusaki, H. \& Koppman, H. Sertoli differentiation is induced both cell-autonomously and through prostaglandin signaling during mammalian sex determination. Developmental Biology 287, 111-124 (2005).

12. Wagner, T., Wirth, J., Meyer, J., Zabel, B., Held, M., Zimmer, J., Pasantes, J., Bricarelli, F.D., Keutel, J., Hustert, E., Wolf, U., Tommerup, N., Schempp, W. \& Scherer, G. Autosomal sex reversal and campomelic dysplasia are caused by mutations in and around the SRY-related gene SOX9. Cell 79, 1111-1120 (1994) DOI.org/10.1016/0092-8674(94)90041-8.

13. Swain, A., Zanaria, E., Hacker, A., Lovell-Badge, R. \& Camerino, G. Mouse Dax 1 expression is consistent with a role in sex determination as well as in adrenal and hypothalamus function. Nat. Genet. 12, 404-409 (1996).

14. Zanaria, E., Muscatelli, F., Bardoni, B., Strom, T.M., Guioli, S., Guo, W., Lalli, E., Moser, C., Walker, A.P., McCabe, E.R., Meitinger, T., Monaco, A., Sassone-Corsi, P. \& Camerino, G. An unusual member of the nuclear hormone receptor superfamily responsible for X-linked adrenal hypoplasia congenita. Nature 372, 635-641 (1994).

15. Bardoni, B., Zanaria, E, Guioli, S., Floridia, G., Worley, K.C., Tonini, G, Ferrante, E., Chiumello, G., McCabe, E.R.B., Fraccaro, M., Zuffardi, O. \& Carmerino, G. A dosage sensitive locus at chromosome Xp21 is involved in male to female sex reversal. Nat. Genet. 7, 497-501 (1994).

16. Muscatelli, F., Strom, T.M., Walker, A.P., Zanaria, E., Recan, D., Meindl, A., Bardoni, B., Guioli, S., Zehetner, G., Rabl, W., Schwarz, H.P., Kaplan, J.C. \& Camerino, G. Mutations in the DAX1 gene give rise to both $\mathrm{X}$-linked adrenal hypoplasia congenita and hypogonadotropic hypogonadism. Nature 372, 672-676 (1994).

17. Meeks, J.J., Weiss, J. \& Jameson, J.L. Dax 1 is required for testis determination. Nat. Genet. 34, 32-33 (2003)

18. Raffin-Sanson, M.L., Oudet, B., Salenave, S., Brailly-Tabard, S., Pehuet, M., Christin-Maitre, S., Morel, Y. \& Young, J. A man with a DAX1/NR0B1 mutation, normal puberty, and an intact hypothalamic-pituitary-gonadal axis but deteriorating oligospermia during long-term follow-up. European Journal of Endocrinology 168, K45-K50 (2013) DOI: 10.1530/eje-12-1055.

19. Mou, L., Xie, N., Yang, L., Liu, Y., Diao, R., Cai, Z., Li, H. \& Gui, Y. A Novel Mutation of DAX-1 Associated with Secretory Azoospermia. PLoS ONE 10, e0133997 (2015) DOI: 10.1371/ journal.pone.0133997.

20. Ponikwicka-Tyszko, D., Kotula-Balak, M., Jarzabek, K., Bilinska, B. \& Wolczynski, S. The DAX1 mutation in a patient with hypogonadotropic hypogonadism and adrenal hypoplasia congenita causes functional disruption of induction of spermatogenesis. Journal of Assisted Reproduction and Genetics 29,811-816 (2012). DOI: 10.1007/s10815-012-9778-y.

21. Ludbrook, L.M., Bernard, P., Bagheri-Fam, S., Ryan, J., Sekido, 
R., Wilhelm, D., Lovell-Badge, R. \& Harley, V.R. Excess DAX1 leads to XY ovotesticular disorder of sex development (DSD) in mice by inhibiting steroidogenic factor-1 (SF1) activation of the testis enhancer of SRY-box-9 (Sox9). Endocrinology 153, 19481958 (2012). Epub 2012/02/02. DOI: 10.1210/en.2011-1428

22. Svingen, T. \& Koopman, P. Building the mammalian testis: origins, differentiation, and assembly of the component cell populations. Genes \& Development. 27, 2409-2426 (2013). DOI: 10.1101/ gad.228080.113.

23. Windley, S.P. \& Wilhelm, D. Signaling Pathways Involved in Mammalian Sex Determination and Gonad Development. Sexual Development. 9, 297-315 (2015).

24. Bendsen, E., Byskov, A.G., Laursen, S.B., Larsen, H.P., Andersen, C.Y. \& Westergaard, L.G. Number of germ cells and somatic cells in human fetal testes during the first weeks after sex differentiation. Human Reproduction 18,13-18 (2003).

25. Magre, S. \& Jost, A. The initial phases of testicular organogenesis in the rat. An electron microscopy study. Arch. Ant. Microsc. Morphol. Exp. 69, 297-318 (1980).

26. Brennan, J., Karl, J. \& Capel, B. Divergent Vascular Mechanisms Downstream of Sry Establish the Arterial System in the XY Gonad. Developmental Biology 244, 418-428 (2002).

27. Coveney, D., Cool, J., Oliver, T. \& Capel, B. Four-dimensional analysis of vascularization during primary development of an organ, the gonad. Proceedings of The National Academy of Sciences of the USA 105,7212-7217 (2008).

28. Codesal, J., Regadera, J., Nistal, M., Regadera-Sejas, J. \& Paniagua, R. Involution of human fetal Leydig cells. An immunohistochemical, ultraestructural and quantitative study. Journal of Anatomy. 172, 103-114 (1990).

29. Feng, S., Ferlin, A., Truong, A., Bathgate, R., Wade, J.D., Corbett, S., Han, S., Tannour-Louet, M., Lamb, D.J., Foresta, C. \& Agoulnik, A. INSL3/RXFP2 Signaling in Testicular Descent: Mice and Men. Annals of the New York Academy of Sciences 1160,197-204 (2009).

30. Karl, J. \& Capel, B. Sertoli Cells of the Mouse Testis Originate from the Coelomic Epithelium. Developmental Biology 203, 323-333 (1998).

31. Merchant-Larios, H. \& Moreno-Mendoza, N. Mesonephric Stromal Cells Differentiate into Leydig Cells in the Mouse Fetal Testis. Experimental Cell Research 244, 230-238 (1998).

32. DeFalco, T., Takahashi, S. \& Capel, B. Two distinct origins for Leydig cell progenitors in the fetal testis. Developmental Biology. 352,14-26 (2011).

33. Zhang, L., Chen, M., Wen, Q., Li, Y., Wang, Y., Wang, Y., Qin, Y., Cui, X., Yang, L. \& Huff, V. Reprogramming of Sertoli cells to fetal-like Leydig cells by Wt1 ablation. Proceedings of the National Academy of Sciences 112, 4003-4008 (2015).

34. Colvin, J.S., Green, R.P., Schmahl, J., Capel, B. \& Ornitz, D.M. Male-to-female sex reversal in mice lacking fibroblast growth factor 9. Cell 104,875-889 (2001).

35. Clark,A.M., Garland, K.K. \& Russell,L.D. Deserthedgehog(Dhh) gene is required in the mouse testis for formation of adult-type Leydig cells and normal development of peritubular cells and seminiferous tubules. Biology of Reproduction 63,1825-1838. (2000).

36. Yao, H.H., Whoriskey, W. \& Capel, B. Desert Hedgehog/Patched 1 signaling specifies fetal Leydig cell fate in testis organogenesis. Genes \& Development 16,1433-1440 (2002).

37. Pask, A. The Reproductive System. In: Wilhelm D, Bernard P, editors. Non-coding RNA and the Reproductive System 1-12. (Dordrecht: Springer Netherlands, 2016).

38. Eicher, E.M. \& Washburn, L.L. Genetic control of primary sex determination in mice. Annual Review of Genetics 20, 327-360 (1986).

39. McElreavey, K., Vilain, E., Abbas, N., Herskowitz, I. \& Fellous, M. A regulatory cascade hypothesis for mammalian sex determination: SRY represses a negative regulator of male development. Proceedings of The National Academy of Sciences of the USA 90, 3368-3372 (1993).

40. Parma, P., Radi, O., Vidal, V., Chaboissier, M.C., Dellambra, E., Valentini, S., Guerra, L., Schedl, A. \& Camerino, G. R-spondin1 is essential in sex determination, skin differentiation and malignancy. Nature Genetics 38, 1304-1309 (2006).

41. Tomizuka, K., Horikoshi, K., Kitada, R., Sugawara, Y., Iba, Y., Kojima, A., Yoshitome, A., Yamawaki, K., Amagai, M., Inoue, A., Oshima, T. \& Kakitani, M. R-spondin1 plays an essential role in ovarian development through positively regulating Wnt-4 signaling. Human Molecular Genetics 17,1278-1291 (2008).

42. Schmidt, D., Ovitt, C.E., Anlag, K., Fehsenfeld, S., Gredsted, L., Treier, A.C. \& Treier, M. The murine winged-helix transcription factor Foxl2 is required for granulosa cell differentiation and ovary maintenance. Development 131: 933-942 (2004).

43. Matson, C.K., Murphy, M.W., Sarver, A.L., Griswold, M.D., Bardwell, B.J. \& Zarkower, D. DMRT1 prevents female reprogramming in the postnatal mammalian testis. Nature 476,101104 (2011).

44. Uhlenhaut, N.H., Jakob, S., Anlag, K., Eisenberger, T., Sekido, R., Kress, J., Treier, A.C., Klugmann, C., Klasen, C., Holter, N.I., Riethmacher, D., Schütz, G., Cooney, A.J., Lovell-Badge, R. \& Treier, M. Somatic Sex Reprogramming of Adult Ovaries to Testes by FOXL2 Ablation. Cell 39,1130-1142 (2009).

45. Yu, M., Wang, J., Liu, W., Qin, J., Zhou, Q., Wang, Y., Huang, H., Chen, W. \& Ma, C. Effects of tamoxifen on the sex determination gene and the activation of sex reversal in the developing gonad of mice. Toxicology 321,89-95 (2014).

46. Couse, J.F., Hewitt, S.C., Bunch, D.O., Sar, M., Walker, V.R., Davis, B.J. \& Korach, K.S. Postnatal Sex Reversal of the Ovaries in Mice Lacking Estrogen Receptors $\alpha$ and $\beta$. Science 286, 23282331 (1999).

47. Nelson, S.M., Telfer, E.E. \& Anderson, R.A. The ageing ovary and uterus: new biological insights. Human Reproduction Update 19, 67-83 (2013). DOI: 10.1093/humupd/dms043.

48. Chen, Y., Breen, K. \& Pepling, M.E. Estrogen can signal through multiple pathways to regulate oocyte cyst breakdown and primordial follicle assembly in the neonatal mouse ovary. Journal of Endocrinology 202,407-417 (2009).

49. Merchant-Larios, H. \& Chimal-Monroy, J. in Developments in 
Ultrastructures of Reproduction 55-63 (eds. P.M. Motta, \& M. Malpighi, 1989).

50. Satoh, M. Histogenesis and organogenesis of the gonad in human embryos. Journal of Anatomy 177, 86-107 (1991).

51. Edson, M.A., Nagaraja, A.K. \& Matzuk, M.M. The Mammalian Ovary from Genesis to Revelation. Endocrine Reviews 30(6):624712 (2009). DOI: 10.1210/er.2009-0012.

52. Zuckerman, S. The number of oocytes in the mature ovary. Recent Progress in Homone Research. 6, 63-108 (1951).

53. Ozakpinar, O.B., Maurer, A.M. \& Ozsavci, D. Ovarian stem cells: From basic to clinical applications. World Journal of Stem Cells 7,757-768 (2015) DOI: 10.4252/wjsc.v7.i4.757.

54. Zhang, H., Zheng, W., Shen, Y., Adhikari, D., Ueno, H. \& Liu, K. Experimental evidence showing that no mitotically active female germline progenitors exist in postnatal mouse ovaries. Proceedings of the National Academy of Sciences of the United States of America 109,12580-12585 (2012) DOI: 10.1073/pnas.1206600109.

55. Koubova, J., Menke, D.B., Zhou, Q., Capel, B., Griswold, M.D.
\& Page, D.C. Retinoic acid regulates sex-specific timing of meiotic initiation in mice. Proceedings of the National Academy of Sciences of the United States of America 103, 2474-2479(2006) DOI: $10.1073 /$ pnas.0510813103.

56. Bowles, J., Knight, D., Smith, C., Wilhelm, D., Richman, J., Mamiya, S., Yashiro K., Chawengsaksophak, K., Wilson, M.J., Rossant, J. \& Hamada, H. \& Koopman, P. Retinoid signaling determines germ cell fate in mice. Science 312, 596-600 (2006).

57. Culty, M. Gonocytes, from the Fifties to the Present: Is There a Reason to Change the Name? Biology of Reproduction 46, 1-6 (2013). DOI: 10.1095/biolreprod.113.110544.

58. Lee, P.A., Houk, C.P., Ahmed, S.F. \& Hughes, I.A. International Consensus Conference on Intersex organized by the Lawson Wilkins Pediatric Endocrine Society and the European Society for Pediatric Endocrinology. Consensus Statement on Management of Intersex Disorders. International Consensus Conference on Intersex. Pediatrics 118, e488-e500 (2006). DOI: 10.1542/ peds.2006-0738. 